\title{
Non-linearities in regional growth: A non-parametric approach ${ }^{*}$
}

\author{
Marcos Sanso-Navarro ${ }^{1}$, María Vera-Cabello ${ }^{1,2}$ \\ ${ }^{1}$ Departamento de Análisis Económico, Universidad de Zaragoza, Facultad de Economía y Empresa Gran Vía 2, \\ Zaragoza 50005, Spain (e-mail: marcossn@unizar.es, mvera@unizar.es) \\ ${ }^{2}$ Centro Universitario de la Defensa de Zaragoza, Zaragoza, Spain
}

Received: 25 March 2013 / Accepted: 31 January 2014

\begin{abstract}
This paper analyses the determinants of regional economic growth in the European Union adopting a non-parametric approach. Although the local-linear kernel estimator applied does not explicitly take into account the spatial dimension of the data, it is found to be consistent in our context. In addition, the geographically weighted regression turns out to be less efficient. We obtain evidence of a non-linear relationship between regional growth and its determinants in the form of parameter heterogeneity and threshold effects. These non-linearities mainly affect the initial productivity of labour, the human capital endowment and, as a novelty, the level of infrastructures.
\end{abstract}

JEL classification: $\mathrm{C} 14, \mathrm{C} 20, \mathrm{O} 18, \mathrm{R} 11$

Key words: Regional growth, non-parametric methods, variable selection, non-linearities

\section{Introduction}

Since the mid-1950s, there has been widespread interest in identifying the drivers of economic growth, both from a theoretical and an empirical point of view. Although the first neoclassical model explained long-run growth with exogenous forces, growth theory took a great leap forward when the different engines of growth were made endogenous. On the empirical side, a variety of methods have been applied to test the implications of these theoretical models or to reveal the relevant variables for growth: cross sectional regressions, time series, panel data models and, more recently, model averaging techniques.

The geographic dimension of the data in empirical growth studies attracted greater attention after theoretical models shifted their object of analysis from countries to regions (Barro and

* The authors have benefited from the valuable comments of the editor (J. Paul Elhorst), three anonymous referees, Daniel Arribas-Bel, Christopher Parmeter, Domingo Pérez, Marcos Sanso and Fernando Sanz. All of them have allowed us to greatly improve previous versions of the manuscript. Financial support from Ministerio de Ciencia e Innovación (ECO2009-09332, ECO2009-13675 and ECO2011-22650 projects), Ministerio de Educación (Grant AP2008-03561) and the Regional Government of Aragón (ADETRE Research Group) is also acknowledged. 
Sala-i-Martín 1991). More recently, and given that existing growth theories did not account for the spatial patterns present in the data, López-Bazo et al. (2004) have proposed a model with regional spillovers caused by physical capital investment and where the initial level of productivity and its growth in neighbouring regions also play an important role. In this same line, Ertur and Koch (2007) have developed a model that explicitly accounts for technological interdependence across economies as well as for physical and human capital externalities. The necessity of addressing spatial dependence between regions in empirical analyses has led to an upsurge in the application of spatial econometrics methods.

The assumption of linearity when specifying growth regressions was called into question after the work of Durlauf and Johnson (1995). Moreover, the new growth theory predicts a non-linear relationship between growth and some of its determinants (Masanjala and Papageorgiou 2004). Against this background, the use of semi-parametric and non-parametric methods is becoming increasingly popular in growth empirics due to their flexibility. The main reason is that they are suitable for the introduction of heterogeneity into growth regressions, as they allow for different parameters across units.

Economic cohesion and convergence between the different areas of the European Union (EU) have been two priorities for policy-makers during the processes of integration and enlargement. This explains why the analysis of regional growth in the EU has attracted a great deal of attention (see Crespo-Cuaresma et al. 2014; and the references therein). In line with the antecedents mentioned above, some of the studies carried out have tried to reveal the presence of non-linear relationships between growth and its determinants in this geographical context. For example, Azomahou et al. (2011) provide evidence of a non-linear convergence process across European regions that depends on national characteristics using a semi-parametric partially linear model. Applying the same methodology, Fotopoulos (2012) concludes that non-linearities affect both the initial level of income per capita and self-employment rates. A common feature of these two studies is that they do not control for spatial effects.

In order to simultaneously deal with the presence of non-linearities and spatial dependence, Basile and Gress (2005), Basile (2008) and Basile et al. (2012) implement semi-parametric spatial models that, broadly speaking, consist of a non-parametric specification of the conditional $\beta$-convergence regression (Barro and Sala-i-Martín 1991; Mankiw et al. 1992) and the parametrization of regional dependencies through spatial lags of the growth rates, the explanatory variables and the error term. These studies find the presence of non-linearities, mainly affecting the initial GDP per capita and the physical and human capital endowments. Adopting a distributional approach, and using non-parametric methods, Basile (2009) only assigns a marginal role to non-linearities in the accumulation of physical capital while Fiaschi and Lavezzi (2007) find that the sectoral composition induces non-linear growth patterns. The latter authors also conclude that spatial effects are not statistically significant.

In the present paper, we contribute to the empirical literature on regional growth and its determinants in the EU by determining not only which variables are relevant for explaining growth, but also which of them have a non-linear relationship with it. The interest of this question is threefold. First, identifying these non-linearities is necessary in order to extend the model space of model averaging exercises when searching for robust growth determinants. Second, it is advisable to consider the possible presence of non-linear relationships between the variables before specifying a model of spatial dependence. Third, the heterogeneity of the effects induced by regional growth determinants should be taken into account for policy design.

We have analysed the possible non-linear influence of regional growth determinants through the application of non-parametric kernel estimation methods that are useful in contexts of parameter heterogeneity or when the appropriate functional form is not known. The results obtained from these estimators are not conditioned by the specification of the spatial dependence (Halleck Vega and Elhorst 2013). In addition, their use allows us to mitigate the trade-off that 
exists when using semi-parametric methods between the determination of the bandwidth parameters - or, alternatively, the identification of non-linearities - and the estimation of spatial parameters (Basile and Gress 2005).

Although kernel regressions do not explicitly control for spatial dependencies across observations, their estimates can still be consistent and asymptotically normal when this feature is present in the data (Robinson 2011; Jenish 2012). For this reason, we have studied the consistency of the local-linear kernel estimator through a comparison of its results with those obtained from the application of a non-parametric estimation method that explicitly takes into account the spatial dimension of the data: the geographically weighted regression (GWR; Brunsdon et al. 1996). This is the first time that these alternative methods have been compared and can be considered as an empirical check of the theoretical results in Jenish (2012) in a regional data context. Apart from finding that the local-linear kernel estimator is consistent, GWR also turns out to be less efficient in our context.

The rest of the paper is structured as follows. Section 2 briefly presents both the theoretical and empirical backgrounds, the data sources and the variables included in the analysis. Section 3 explains the non-parametric methods applied. The assessment of the relevant regional growth determinants and their non-linear influence is carried out in Section 4. Finally, Section 5 concludes.

\section{Background and data}

\subsection{Theoretical and empirical backgrounds}

The first theoretical regional growth model dates back to Borts and Stein (1964). It consists of an extension of the neoclassical paradigm (Solow 1956) that allows for factor mobility. The main assumption behind neoclassical models was the formulation of a production function with constant returns to scale. Given its simplicity and empirical explanatory power, this type of model was standard in the economic growth literature until the arrival of endogenous growth models led to a revolution in the field.

The fundamental proposition of endogenous growth models is that growth is a result of deliberate decisions of rational agents with respect to the accumulation of physical (Romer 1986) and human (Lucas 1988) capital, the allocation of resources to R\&D activities (Romer 1990) or public expenditure on infrastructures (Barro 1990). In particular, these decisions have consequences on the general equilibrium that increase the productivity of labour which, in turn, generates economic growth.

A link between the endogenous growth models and regional models of growth has been established because production activities and knowledge tend to be geographically concentrated and distributed in space. Early studies identified the availability of inputs and access to output markets as key reasons for the spatial agglomeration of industries. In this line, the idea that informational spillovers improve productivity in agglomerations is generalized by the new economic geography (NEG; Krugman 1991) using endogenous growth modelling tools. Therefore, the basic mechanisms of knowledge creation, accumulation and diffusion have been regionalized in the NEG, providing insights into how geographical space can influence growth.

The predictions from regional growth models have traditionally been tested using growth regressions (Barro and Sala-i-Martín 1991; Mankiw et al. 1992), which take the following form:

$$
g_{i}=\beta_{0}+\beta \mathbf{N}_{i}+\gamma \mathbf{Z}_{i}+u_{i} ; \quad i=1, \ldots, n
$$

where $g_{i}$ is region $i$ 's average growth rate of real output over a given period of time, $\beta_{0}$ is a constant and $\mathbf{N}_{i}$ is a vector of neoclassical growth determinants reflecting the initial level of 
income, the endowment of physical capital and the population growth rate. $\mathbf{Z}_{i}$ denotes a vector of additional control variables associated with alternative growth theories that determine regional steady state differences. The range of potential factors that can be included in this vector is very large, so many combinations have been considered in the literature. Finally, $u_{i}$ is a zero mean additive error and $n$ is the number of regions in the sample.

This workhorse of empirical growth research has been extended to include non-linearities and dependence across regions in the form of spatial lags of both the endogenous and exogenous variables and of the error term. Although we are not unaware of the presence of spatial dependence between observations when dealing with regional data, in this paper, we focus on the analysis of non-linearities in the relationship between growth and its determinants. As is described in the methodological section below, this is done through the application of nonparametric estimation methods that are consistent in the presence of spatial dependence.

\subsection{Data and variables}

The analysis has been carried out with cross-sectional data for 255 NUTS $_{2}$ regions $^{1}$ (EU 27 countries). The dependent variable is the average growth rate of real gross value added (GVA) per worker over the period 1995-2010, calculated with data from Cambridge Econometrics. The validity of the different growth theories and the existence of underlying non-linear effects have been studied with part of the data compiled by Crespo-Cuaresma and Feldkircher (2013). ${ }^{2}$ Following their analysis, empirical proxies for growth determinants have been taken at the beginning of the period analysed to try to mitigate endogeneity problems. In order to avoid the presence of multicollinearity and the 'curse of dimensionality', ${ }^{3}$ only those variables that are representative of a given engine of growth in general terms and with a low correlation with the other regressors have been considered.

The first group of growth determinants corresponds to the basic neoclassical model ('Solow'). In line with the description of $\mathbf{N}_{i}$ in Equation (1), the initial level of real GVA per worker (GVAPW), the population growth $\operatorname{rate}^{4}$ (GPOP) and the share of gross fixed-capital formation over total GVA (SHGFCF) have been included.

Endogenous growth theories give a prominent role to human capital accumulation and R\&D activities ('Knowledge'). The former has been reflected by the share of highly educated people in the working-age population (SHSH). R\&D activities and their innovation results have been proxied in our empirical analysis by the human resources devoted to science and technology (HRSTCORE), the total number of patents (PATENT) and the share of patents in high technology over the total (PATENTSHHT).

We have also tried to reflect the influence that different types of infrastructures can exert on growth through agglomeration forces and knowledge spillovers. With this aim, the level of transport infrastructures has been measured by the airport (AIRPORTDENS), road (ROADDENS) and rail

\footnotetext{
${ }^{1}$ The choice of the areal unit of analysis is an important issue in empirical studies with aggregate spatial data sources. This is because different levels of aggregation can lead to different results, the so-called modifiable areal unit problem (MAUP; Unwin 1996). NUTS is the French acronym for 'Nomenclature of Territorial Units for Statistics', a hierarchical classification established by EUROSTAT to provide comparable regional breakdowns of EU member states. NUTS 2 regions are defined according to a formal rather than a functional criteria, because they correspond to the level used for the implementation of regional policies. This institutional breakdown may influence the results, although to a lesser extent than if we were interested in modelling and analysing regional spatial dependence.

${ }^{2}$ Further details (data sources and variables description) to those presented in this section can be found in the material available at http://qed.econ.queensu.ca/jae/datasets/cuaresma002.

3 This problem arises with the non-parametric kernel regression methods applied and consists of the rapid increase of the variance of the estimates with the number of variables included in the model.

${ }^{4}$ We have added 0.05 to the population growth rate $(n)$ to proxy the effective rate of depreciation in neoclassical growth models $(n+g+\delta)$. We will use these two terms interchangeably in what follows.
} 
(RAILDENS) densities. In addition, a typology of the level of firms' telecommunications access and uptake (TELF) has also been introduced into our empirical specification.

Socio-geographic variables have also been included in an attempt to proxy for further spatial aspects. We have considered employment density (EMPDENS), the distance from the capital (DISTCAP), the sum of all weighted hazard values (HAZARD) and the settlement structure (SETTL). Dummies for coastal (REGCOAST), border (REGBORDER) and 'objective 1' (REGOBJ1) regions have also been introduced as explanatory variables. Lastly, the unemployment rate (URT) has been included to reflect regional labour market characteristics.

\section{Non-parametric kernel regression methods}

To a great extent, the empirical analysis carried out in this study follows the approach proposed by Henderson et al. (2012). These authors exploited the fact that the relevance and non-linear influence of the explanatory variables in non-parametric kernel regressions are revealed by their corresponding bandwidths when these parameters are determined using a least-squares crossvalidation selection method.

The non-parametric specification of growth regressions in (1) is:

$$
g_{i}=m\left(\mathbf{X}_{i}\right)+\varepsilon_{i} ; \quad i=1, \ldots, n,
$$

where $\mathbf{X}_{\mathbf{i}}=\left(x_{i 1}, x_{i 2}, \ldots, x_{i q}\right)$ is a vector of $q$ variables related to growth (the union of $\mathbf{N}_{i}$ and $\left.\mathbf{Z}_{i}\right)$ and $\varepsilon_{i}$ is a zero mean additive error. $m(\cdot)$ is the smooth unknown function for the conditional mean:

$$
m(\mathbf{x})=E\left[g_{i} \mid \mathbf{X}_{i}=\mathbf{x}\right],
$$

$\mathbf{x}=\left(x_{1}, x_{2}, \ldots, x_{q}\right)$ denotes the vector of growth determinants at which the conditional mean is evaluated.

The flexibility of non-parametric estimation methods derives from the fact that it is not necessary to make any assumption about the functional form of the conditional mean or about the distribution of the error term.

One alternative for estimating the conditional mean function is by locally averaging the growth rates of the regions that are similar in terms of the values taken by their growth determinants. This method is known as the local-constant (or Nadaraya-Watson) kernel estimator:

$$
\hat{m}(\mathbf{x})=\sum_{i=1}^{n} w_{i} g_{i}
$$

Weights are non-negative, their sum is equal to one and they are given by

$$
w_{i}=\frac{K\left(\frac{\mathbf{X}_{i}-\mathbf{x}}{\mathbf{h}}\right)}{\sum_{j=1}^{n} K\left(\frac{\mathbf{X}_{j}-\mathbf{x}}{\mathbf{h}}\right)},
$$

with

$$
K\left(\frac{\mathbf{X}_{i}-\mathbf{x}}{\mathbf{h}}\right)=k\left(\frac{X_{i 1}-x_{1}}{h_{1}}\right) \cdot k\left(\frac{X_{i 2}-x_{2}}{h_{2}}\right) \ldots k\left(\frac{X_{i q}-x_{q}}{h_{q}}\right),
$$

and $k(\cdot)$ being a kernel function. 
That is, the local-constant kernel estimator at $\mathbf{x}$ takes the average of the $g_{i}$ values for the regions such that their $\mathbf{X}_{i}$ are in a neighbourhood of $\mathbf{x}$. The amount of information used to calculate the local average is determined by the bandwidths $\mathbf{h}=\left(h_{1}, h_{2}, \ldots, h_{q}\right)$. A data-driven method for selecting these smoothing parameters is least-squares cross-validation, which consists of choosing $\mathbf{h}$ to minimize the following criterion:

$$
C V(\mathbf{h})=\frac{1}{n} \sum_{i=1}^{n}\left(g_{i}-\hat{m}_{-i}\left(\mathbf{X}_{i}\right)\right)^{2} M\left(\mathbf{X}_{i}\right) ; 0 \leq M(\cdot) \leq 1,
$$

where $M(\cdot)$ is a weighting function and

$$
\hat{m}_{-i}\left(\mathbf{X}_{i}\right)=\sum_{l \neq i}^{n} \frac{g_{l} K\left(\frac{\mathbf{X}_{i}-\mathbf{X}_{l}}{\mathbf{h}}\right)}{\sum_{l \neq i}^{n} K\left(\frac{\mathbf{X}_{i}-\mathbf{X}_{l}}{\mathbf{h}}\right)}
$$

In other words, the criterion minimized by the cross-validation bandwidth selection is a trimmed version of the sum of squared residuals from a leave-one-out estimator of the conditional mean function. Following Li and Racine (2004), we have set $M(\cdot)=1$.

Least-squares cross-validation bandwidth selection, in conjunction with the local-constant kernel estimator, is capable of automatically reducing the dimension of the problem when some of the regressors are irrelevant. More specifically, the irrelevant variables will be smoothed out as

$$
k\left(\frac{X_{i s}-x_{s}}{h_{s}}\right) \rightarrow k(0) \quad \text { when } \quad h_{s} \rightarrow \infty ; \quad s=1,2, \ldots, q
$$

Instead of the local-constant approximation, a linear regression through the regions with growth determinants in the same neighbourhood can be fitted. When a weighting function is included with this purpose, the method is called the local-linear kernel estimator. The idea is to estimate

$$
g_{i}=a+\mathbf{b}^{\prime}\left(\mathbf{X}_{i}-\mathbf{x}\right)+e_{i}
$$

As $\left(\mathbf{X}_{i}-\mathbf{x}\right)$ is used as the regressor, the intercept equals the conditional mean in (3). The estimation is based on solving the following problem:

$$
\min _{a, b} \sum_{i=1}^{n}\left(g_{i}-a-\mathbf{b}^{\prime}\left(\mathbf{X}_{i}-\mathbf{x}\right)\right)^{2} K\left(\frac{\mathbf{X}_{i}-\mathbf{x}}{\mathbf{h}}\right)
$$

It has been demonstrated that the solutions $\hat{a}=\mathrm{a}(\mathbf{x})$ and $\hat{\mathbf{b}}=b(\mathbf{x})$ are consistent estimators of the conditional mean function and of its partial derivative $\left(m^{(1)}(\mathbf{x})=\partial m(\mathbf{x}) / \partial \mathbf{x}\right)$, respectively (Li and Racine 2007). Due to its analogy to local least-squares, the local-linear estimation method nests the least-squares estimator as a special case for sufficiently large values of the bandwidth parameters.

Therefore, what is important for the main aim of this paper is that the least-squares cross-validation method for bandwidth selection in the local-linear framework has the ability to select a large value of $h_{s}$ when the conditional mean function is linear in $x_{s}$. On the contrary, it will select small values of the bandwidth parameter for regressors that have a non-linear relationship with growth. 
To sum up, the least-squares cross-validation bandwidth parameters for the local-constant regression will be used in order to draw conclusions regarding the relevance of regional growth determinants. The bandwidths for the local-linear estimation will allow us to determine its non-linear influence. Given that the kernel function considered in the empirical analysis is the Gaussian one:

$$
k(v)=\frac{1}{\sqrt{2 \pi}} e^{-\frac{v^{2}}{2}} ; \quad-\infty<v<\infty,
$$

we will conclude that a continuous growth determinant enters the conditional mean in an irrelevant fashion (local-constant regression) or linearly (local-linear) if its corresponding bandwidth parameter is more than twice its sample standard deviation. The versions of the estimation methods applied are those that allow us to handle both continuous and discrete variables in $\mathbf{X}_{i}{ }^{5}$ A performance evaluation of this procedure with relatively large numbers of relevant and irrelevant regressors in small samples can be found in Henderson et al. (2012).

Before proceeding with the empirical analysis, it is worth noting that these estimation methods are based on the implicit assumption that each observation is independent and provides unique information. Spatial autocorrelation among regions implies a lack of independence and may arise because of measurement problems, boundary mismatches or the presence of spillovers and externalities. This dependence can result in misguided inferences and interpretations when using standard parametric estimation methods. Nevertheless, this is not necessarily the case for the local-constant and local-linear estimators. The conditions for their consistency and asymptotic normality when applied to spatially dependent data have been established by Robinson (2011) and Jenish (2012), respectively. Therefore, these properties can be added to the arguments in McMillen (2010) to advocate the use of non-parametric methods when dealing with spatial data.

\section{A non-parametric approach to regional growth determinants}

\subsection{Assessment of their relevance and non-linear influence}

Our empirical analysis begins with the calculation of the bandwidth parameters with a leastsquares cross-validation selection rule adopting a 'between-country' perspective, considering the raw data without controlling for country-specific characteristics. The corresponding descriptive statistics (mean and standard deviation) and the bandwidths obtained for each potential regional growth determinant are reported in the first four columns of Table 1.

The bandwidth parameters calculated for the local-constant estimation method are lower than two times the sample standard deviation for all the variables considered. Hence, it can be stated that all the growth determinants included in our empirical specification are relevant for explaining regional growth differences in the EU during the period 1995-2010. This finding not only reflects the importance of neoclassical growth variables, but also the role played by those determinants highlighted by the endogenous growth theories and regional growth models like transport and telecommunications infrastructures and socio-geographic factors.

Having identified the relevant regional growth determinants, the next step in our analysis is to determine which of them exert a non-linear influence. As has been explained in the previous section, this is related to the magnitude of the bandwidth parameter calculated by the least-

5 These non-parametric methods have been implemented using the $n p$ package for the $\mathrm{R}$ software (R Core Team 2013). 


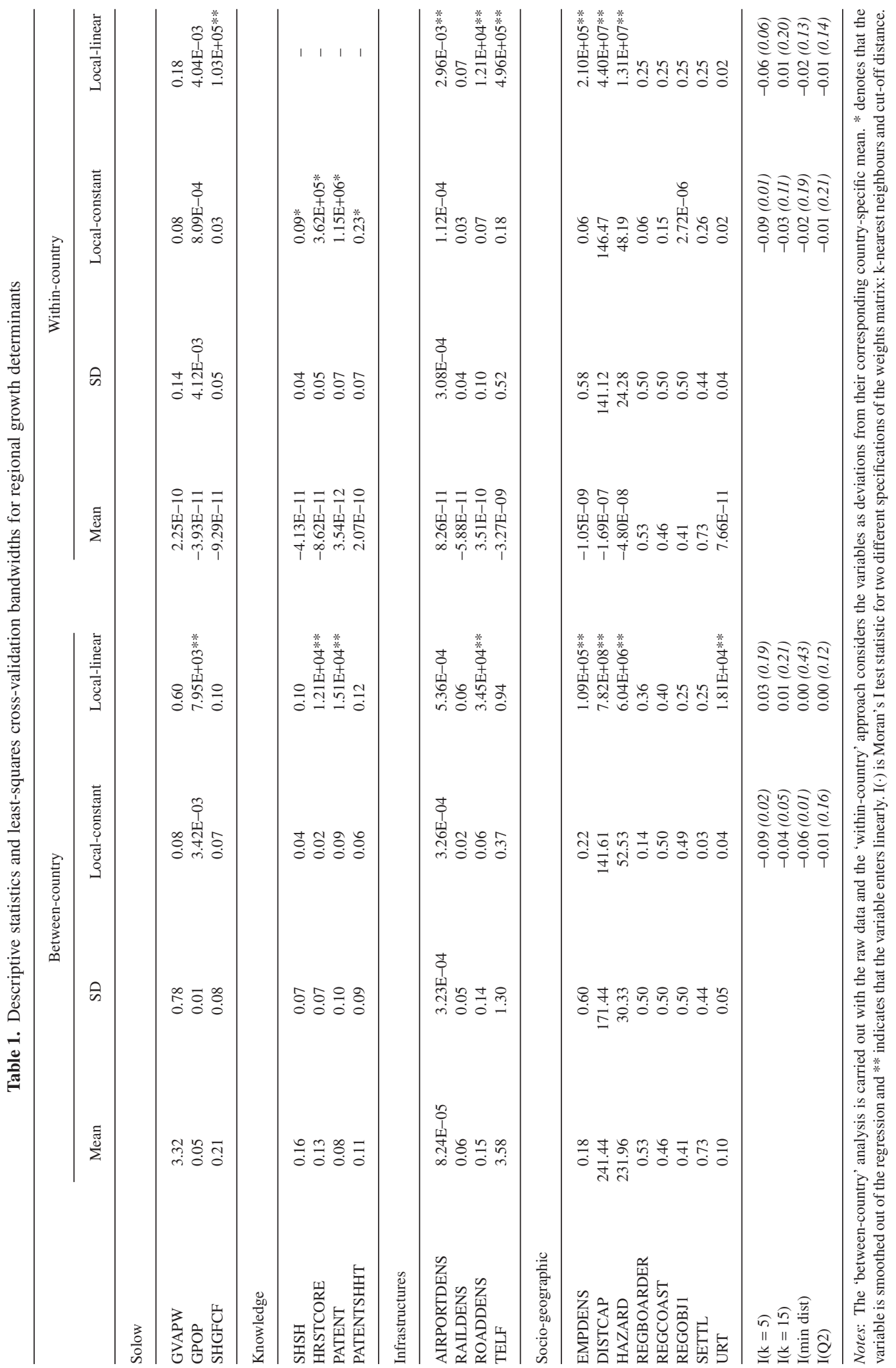


squares cross-validation selection rule for the local-linear kernel regression estimator. The values obtained are reported in the fourth column of Table 1. They suggest that the neoclassical variables that have a non-linear relationship with regional growth are the initial level of GVA per worker and the share of gross fixed-capital formation over total GVA. The share of highly educated people in the working age population and the empirical proxies of the level of infrastructures also exert a non-linear influence on growth. On the contrary, it is concluded that the continuous socio-geographic variables have a linear relationship with growth. With the exception of the share of patents in high technology over the total, this is also true for the variables reflecting $R \& D$ activities and their innovation results.

Both the local-constant and the local-linear kernel estimators assume that the observations are independent and, hence, do not account for the presence of spatial dependence when applied in the present context. In order to analyse the extent to which this method and the empirical specification considered in our analysis capture this feature of European regional data, the global Moran's I test has been calculated for the kernel regression residuals. The null hypothesis of this test is the absence of spatial autocorrelation. The resulting test statistics, along with their $p$-values, are reported for four alternative choices of the spatial weights matrix in the lower panel of Table 1.

Two types of row-standardized weights matrices have been considered, bearing in mind that those based on a contiguity criterion are not suitable for European regions. The first type is made up of the great circle distances between the centroid of a region and those of its five and 15 nearest regions (k-nearest neighbours). The other elements are set to zero. The second type of matrix is also distance-based. The elements on the diagonal are set to zero and a given threshold value determines which regional interactions are assumed to be negligible. We have used two criteria according to which the elements off the diagonal are set to zero: when the distance between regional centroids exceeds $(i)$ the minimum distance for which there is no neighbourless region and (ii) the median of all distances between regions.

The null hypothesis of no residual spatial autocorrelation is rejected at the 5 per cent significance level in two out of the four cases for the local-constant estimation. More importantly, Moran's I test does not reject the null hypothesis at the 10 per cent significance level in the residuals from the local-linear estimation for any of the specifications of the weights matrix. The latter result is more reliable because it has been demonstrated that the local-linear estimator outperforms the local-constant alternative in small samples (Fan and Gijbels 1996). Therefore, the local-linear estimator is better suited to making inferences and assessing model fit.

Up to now, the non-linearities we have found are identified by differences both within and between countries. In order to assess which of these dimensions are driving these results, the same analysis as before has been carried out with the variables expressed as deviations from their corresponding country-specific means. Proceeding in that way, we adopt a 'within-country' perspective that is equivalent to introducing country fixed-effects into the empirical model. The descriptive statistics and bandwidth parameters obtained are reported in the last four columns of Table 1.

It can be concluded from the magnitude of the bandwidths calculated for the local-constant estimator that, once country-specific factors are accounted for, the level of education and R\&D activities and their innovation results are not relevant for explaining regional growth differences in the EU. Hence, knowledge creation and accumulation - the long-run sources of growth for endogenous growth theories - do not explain European regional growth from a 'within-country' perspective. Nevertheless, neoclassical growth variables, the empirical proxies for the level of infrastructures and socio-geographic factors are relevant determinants of regional growth at the country level.

The bandwidth parameters for the local-linear kernel estimation also suggest that, when country-specific factors are controlled for, the initial level of labour productivity has a non-linear 
influence on regional growth. On the contrary, and with the exception of the unemployment rate, the continuous socio-geographic growth determinants tend to have a linear relationship with it. In addition, while the share of gross fixed-capital formation over total GVA is linearly related to growth from a 'within-country' perspective, population growth has a non-linear relationship with it. Although its corresponding bandwidth parameter is very close to the threshold value, rail density is the only proxy for the level of infrastructures that seems to have a non-linear relationship with growth. Therefore, it can be deduced that physical capital investment and infrastructures have a more homogeneous effect on growth at country level.

Finally, Moran's I test is only able to reject the null hypothesis for the local-constant estimation and the weights matrix that takes into account the five nearest neighbours. Nonetheless, it is worth remembering that local-linear kernel regressions are more reliable for making inferences. The null hypothesis is not rejected for the residuals from this estimation in any specification of the weights matrix.

\subsection{Analysing regional heterogeneity}

We also analyse the influence of the regional growth determinants in the EU through their estimated partial effects (gradients) from the local-linear estimator, obtained using the bandwidths reported in Table 1. In what follows, we will focus on the 'between-country' perspective.

Table 2 describes the local-linear partial effects for each continuous regressor included in our empirical specification, including their mean and quartiles and their corresponding bootstrap standard errors. The upper panel refers to the neoclassical growth determinants. The estimated partial effects and their statistical significance provide further evidence of the presence of a convergence process across European regions as they have a negative sign for the initial level of GVA per worker. Also in line with the theoretical prediction of the neoclassical growth model, the effective rate of depreciation has a negative influence on growth, when it is statistically significant. The converse is true for the accumulation of physical capital.

Our results suggest that the educational level has a positive relationship with long-run regional growth in Europe. In addition, the effects on growth of both the human resources devoted to science and technology and the total number of patents are also positive. However, and due to their high standard errors, the partial effects at the three quartiles of the share of patents in high technology over the total are not statistically significant. Hence, it can be concluded that the quantity of R\&D innovation results is more important than their quality for explaining regional growth differences in the EU.

The sign of the statistically significant gradients suggests that transport and telecommunication infrastructures tend to have a positive influence on growth. The exceptions are airport density at the lower quartile and road density at the median and upper quartiles. These results might be pointing to some type of congestion effects. The significance of the gradients for the continuous socio-geographic variables, reported in the lower panel of Table 2, suggests that these variables have a negative influence on growth. This is especially true for the distance of the region from the capital city and the unemployment rate.

Summarizing, the distributions of the estimated gradients lead us to conclude that regional growth in the European Union is driven by the convergence process, human capital accumulation and R\&D activities and their innovation results. In addition, the sign of the partial effects for rail transport infrastructures and the functioning of the labour market and the magnitude of their standard errors suggest that they are explanatory factors of regional growth differences in the EU.

The quartiles reported in Table 2 reinforce the conclusions drawn from the cross-validation bandwidth parameters in Table 1 regarding the kind of influence that regional growth determi- 
Table 2. Partial effects for continuous regional growth determinants

\begin{tabular}{|c|c|c|c|c|c|}
\hline & Mean & Q1 & Q2 & Q3 & IQ range \\
\hline \multicolumn{6}{|l|}{ Solow } \\
\hline GVAPW & $\begin{array}{c}-0.01 \\
(1.97 \mathrm{E}-03)\end{array}$ & $\begin{array}{c}-0.02 \\
(7.14 \mathrm{E}-04)\end{array}$ & $\begin{array}{c}-0.01 \\
(1.47 \mathrm{E}-03)\end{array}$ & $\begin{array}{c}-0.01 \\
(2.55 \mathrm{E}-03)\end{array}$ & 0.01 \\
\hline GPOP & $\begin{array}{c}-0.05 \\
(0.11)\end{array}$ & $\begin{array}{c}-0.20 \\
(0.04)\end{array}$ & $\begin{array}{c}-0.11 \\
(0.08)\end{array}$ & $\begin{array}{c}0.01 \\
(0.08)\end{array}$ & 0.21 \\
\hline SHGFCF & $\begin{array}{c}0.03 \\
(0.01)\end{array}$ & $\begin{array}{c}-0.01 \\
(0.01)\end{array}$ & $\begin{array}{c}0.01 \\
(0.01)\end{array}$ & $\begin{array}{c}0.04 \\
(0.01)\end{array}$ & 0.05 \\
\hline \multicolumn{6}{|l|}{ Knowledge } \\
\hline SHSH & $\begin{array}{c}0.04 \\
(0.01)\end{array}$ & $\begin{array}{c}0.02 \\
(0.01)\end{array}$ & $\begin{array}{c}0.03 \\
(0.01)\end{array}$ & $\begin{array}{c}0.05 \\
(0.01)\end{array}$ & 0.03 \\
\hline HRSTCORE & $\begin{array}{c}0.04 \\
(0.01)\end{array}$ & $\begin{array}{c}0.02 \\
(2.26 \mathrm{E}-03)\end{array}$ & $\begin{array}{c}0.03 \\
(0.01)\end{array}$ & $\begin{array}{c}0.03 \\
(0.01)\end{array}$ & 0.01 \\
\hline PATENT & $\begin{array}{c}0.04 \\
(0.01)\end{array}$ & $\begin{array}{c}1.05 \mathrm{E}-03 \\
(3.06 \mathrm{E}-03)\end{array}$ & $\begin{array}{c}0.01 \\
(3.90 \mathrm{E}-03)\end{array}$ & $\begin{array}{c}0.03 \\
(4.11 \mathrm{E}-03)\end{array}$ & 0.03 \\
\hline PATENTSHHT & $\begin{array}{c}4.55 \mathrm{E}-03 \\
(5.33 \mathrm{E}-03)\end{array}$ & $\begin{array}{c}-4.22 \mathrm{E}-03 \\
(0.01)\end{array}$ & $\begin{array}{l}4.11 \mathrm{E}-03 \\
(0.01)\end{array}$ & $\begin{array}{c}0.01 \\
(0.02)\end{array}$ & 0.01 \\
\hline \multicolumn{6}{|l|}{ Infrastructures } \\
\hline AIRPORTDENS & $\begin{array}{c}1.06 \\
(1.13)\end{array}$ & $\begin{array}{l}-2.11 \\
(0.75)\end{array}$ & $\begin{array}{c}-1.24 \\
(0.74)\end{array}$ & $\begin{array}{c}1.98 \\
(0.55)\end{array}$ & 4.09 \\
\hline RAILDENS & $\begin{array}{c}0.05 \\
(0.01)\end{array}$ & $\begin{array}{c}0.01 \\
(0.01)\end{array}$ & $\begin{array}{c}0.02 \\
(0.01)\end{array}$ & $\begin{array}{c}0.06 \\
(0.03)\end{array}$ & 0.05 \\
\hline ROADDENS & $\begin{array}{c}-0.02 \\
(2.75 \mathrm{E}-03)\end{array}$ & $\begin{array}{c}-0.02 \\
(3.61 \mathrm{E}-03)\end{array}$ & $\begin{array}{c}-0.01 \\
(2.64 \mathrm{E}-03)\end{array}$ & $\begin{array}{c}-0.01 \\
(3.45 \mathrm{E}-03)\end{array}$ & 0.01 \\
\hline TELF & $\begin{array}{c}1.64 \mathrm{E}-04 \\
(3.39 \mathrm{E}-04)\end{array}$ & $\begin{array}{l}-4.11 \mathrm{E}-04 \\
(3.63 \mathrm{E}-04)\end{array}$ & $\begin{array}{l}-7.22 \mathrm{E}-08 \\
(2.75 \mathrm{E}-07)\end{array}$ & $\begin{array}{c}5.95 \mathrm{E}-04 \\
(1.76 \mathrm{E}-04)\end{array}$ & $1.01 \mathrm{E}-03$ \\
\hline \multicolumn{6}{|l|}{ Socio-geographic } \\
\hline EMPDENS & $\begin{array}{c}2.60 \mathrm{E}-03 \\
(2.23 \mathrm{E}-03)\end{array}$ & $\begin{array}{c}-4.14 \mathrm{E}-03 \\
(1.24 \mathrm{E}-03)\end{array}$ & $\begin{array}{c}-1.00 \mathrm{E}-03 \\
(1.67 \mathrm{E}-03)\end{array}$ & $\begin{array}{c}2.28 \mathrm{E}-03 \\
(2.00 \mathrm{E}-03)\end{array}$ & 0.01 \\
\hline DISTCAP & $\begin{array}{l}-3.70 \mathrm{E}-05 \\
(1.06 \mathrm{E}-05)\end{array}$ & $\begin{array}{l}-6.41 \mathrm{E}-06 \\
(2.37 \mathrm{E}-06)\end{array}$ & $\begin{array}{l}-4.06 \mathrm{E}-06 \\
(2.19 \mathrm{E}-06)\end{array}$ & $\begin{array}{c}3.66 \mathrm{E}-06 \\
(2.99 \mathrm{E}-06)\end{array}$ & $1.01 \mathrm{E}-05$ \\
\hline HAZARD & $\begin{array}{l}-3.70 \mathrm{E}-05 \\
(1.04 \mathrm{E}-05)\end{array}$ & $\begin{array}{l}-5.09 \mathrm{E}-05 \\
(1.64 \mathrm{E}-05)\end{array}$ & $\begin{array}{l}-2.55 \mathrm{E}-05 \\
(9.10 \mathrm{E}-06)\end{array}$ & $\begin{array}{l}-1.64 \mathrm{E}-05 \\
(1.26 \mathrm{E}-05)\end{array}$ & $3.45 \mathrm{E}-05$ \\
\hline URT & $\begin{array}{r}-0.03 \\
(0.01)\end{array}$ & $\begin{array}{c}-0.05 \\
(0.03)\end{array}$ & $\begin{array}{c}-0.04 \\
(0.01)\end{array}$ & $\begin{array}{c}-0.02 \\
(0.01)\end{array}$ & 0.03 \\
\hline
\end{tabular}

Notes: Partial effects are the estimated derivatives from the local-linear nonparametric regression adopting a 'betweencountry' perspective. Bootstrap standard errors in parentheses (399 replications).

nants exert. The statistical significance, magnitude and sign of the estimated partial effects confirm the non-linear influence of educational level and airport and rail densities on growth. The linear relationship with growth of the human resources devoted to science and technology, the total number of patents and road density can also be observed.

The assertion that the initial level of GVA per worker has a non-linear relationship with growth, derived from the bandwidth parameters in Table 1, can be called into question when looking at the quartiles of the partial effects for this variable reported in Table 2. Nevertheless, this impression changes when the implied convergence rates are further analysed. Specifically, heterogeneity in annual convergence rates is perceived when comparing the 0.91 per cent in the higher quartile (Etelä-Suomi) with that in the lower quartile of 1.93 per cent (Anatoliki Makedonia, Thraki). The average estimated annual convergence rate for the 255 NUTS 2 
regions in our sample during the period 1995-2010 is 1.80 per cent (Valle d'Aosta). Although this value is slightly lower than the 'expected' rate of 2 per cent in the empirical growth literature (Abreu et al. 2005), it is much closer to this reference value than those reported by recent related studies. In particular, it is lower than the 3.5 per cent estimated by Eckey et al. (2009) and higher than the 0.46 per cent obtained by Basile et al. (2012).

To conclude, we have provided evidence in this subsection regarding the heterogeneity of the estimated partial effects for the continuous growth determinants included in our empirical model. This finding reflects that the relationship between growth and its determinants differs across European regions. On the one hand, this result can be interpreted as evidence in favour of the theoretical models that predict the presence of multiple steady-state equilibria, allowing for the presence of multiple regimes of growth patterns (Azariadis and Drazen 1990; Galor 1996). On the other hand, this finding implies that policy design in the European Union should take into account not only that the regions have different characteristics, but also that the latter influence growth in a different way. Therefore, EU Cohesion Policy must go beyond the 'one-size-fits-all' approach.

\subsection{A comparison with alternative non-parametric methods}

The partial effects reported in Table 2 can be compared with the estimated parameters obtained from the application of a GWR. This technique provides intercept and slope parameters for each region in the sample by running a sequence of local-linear regressions using subsets of data that are close in the geographical space, instead of in the variable space. ${ }^{6}$ That is to say, observations are weighted in accordance with their proximity to region $i$. The estimation of a separate model for each region is considered to be an advantage of this method over the parametric spatial lag and spatial error models. The mean value and three quartiles for the estimated coefficients, as well as their standard errors, are shown in Table 3.

The signs of the estimated coefficients are in line with the theoretical predictions and, more interestingly, their values are of a similar magnitude to the gradients reported in Table 2. Despite this, it would have not been possible to detect any non-linear effect from these coefficients for the initial level of GVA per worker and the share of highly educated people in the working age population. GWR estimates also lead us to some odd results like the prediction of a positive effect on growth of the effective rate of depreciation at its upper quartile.

With the exception of the initial level of labour productivity, physical capital endowment and the telecommunications access and uptake of firms, the statistical significance of the estimated parameters is much lower than that corresponding to the partial effects obtained from the local-linear kernel estimator. For example, the only empirical proxy for R\&D activities and their innovation results that significantly affects growth is the human resources devoted to science and technology in its upper quartile. In addition, and bearing in mind that the regional dummies have not been considered in this estimation, the socio-geographic variables are not considered as being related to growth. The exception is the unemployment rate in its lower quartile.

It can be observed that the global Moran's I test is not able to reject the null hypothesis of no spatial autocorrelation in the residuals for any specification of the weights matrix. Thus, these estimation results can be used as a reference to analyse the extent to which the partial effects obtained with the local-linear regression technique are affected by the presence of spatial dependence between regions. The similarity between the magnitude and the sign of the gradients

\footnotetext{
${ }^{6}$ This estimation method has been implemented with the spgwr package in R (R Core Team 2013). A cross-validation bandwidth selection rule that minimizes the root mean square prediction error of the response variable and a normal kernel function have been used in order to make the results comparable.
} 
Table 3. Estimated coefficients from a geographically weighted regression

\begin{tabular}{|c|c|c|c|c|c|}
\hline & Mean & Q1 & Q2 & Q3 & IQ range \\
\hline \multicolumn{6}{|l|}{ Solow } \\
\hline GVAPW & $\begin{array}{c}-0.02 \\
(1.76 \mathrm{E}-03)\end{array}$ & $\begin{array}{c}-0.02 \\
(1.27 \mathrm{E}-03)\end{array}$ & $\begin{array}{c}-0.02 \\
(1.16 \mathrm{E}-03)\end{array}$ & $\begin{array}{c}-0.02 \\
(3.06 \mathrm{E}-03)\end{array}$ & 0.00 \\
\hline GPOP & $\begin{array}{c}0.15 \\
(0.16)\end{array}$ & $\begin{array}{c}-0.15 \\
(0.19)\end{array}$ & $\begin{array}{c}0.01 \\
(0.13)\end{array}$ & $\begin{array}{c}0.37 \\
(0.16)\end{array}$ & 0.52 \\
\hline SHGFCF & $\begin{array}{c}0.03 \\
(0.01)\end{array}$ & $\begin{array}{c}0.01 \\
(0.01)\end{array}$ & $\begin{array}{c}0.02 \\
(0.01)\end{array}$ & $\begin{array}{c}0.04 \\
(0.01)\end{array}$ & 0.03 \\
\hline \multicolumn{6}{|l|}{ Knowledge } \\
\hline SHSH & $\begin{array}{c}0.01 \\
(0.01)\end{array}$ & $\begin{array}{c}-2.97 \mathrm{E}-03 \\
(0.02)\end{array}$ & $\begin{array}{c}0.01 \\
(0.01)\end{array}$ & $\begin{array}{c}0.01 \\
(0.02)\end{array}$ & 0.01 \\
\hline HRSTCORE & $\begin{array}{c}0.04 \\
(0.01)\end{array}$ & $\begin{array}{c}0.02 \\
(0.02)\end{array}$ & $\begin{array}{c}0.03 \\
(0.02)\end{array}$ & $\begin{array}{c}0.06 \\
(0.01)\end{array}$ & 0.04 \\
\hline PATENT & $\begin{array}{c}-8.22 \mathrm{E}-04 \\
(0.01)\end{array}$ & $\begin{array}{c}-5.93 \mathrm{E}-03 \\
(0.01)\end{array}$ & $\begin{array}{c}-8.73 \mathrm{E}-05 \\
(0.01)\end{array}$ & $\begin{array}{c}3.80 \mathrm{E}-03 \\
(0.01)\end{array}$ & 0.01 \\
\hline PATENTSHHT & $\begin{array}{c}1.84 \mathrm{E}-03 \\
(0.01)\end{array}$ & $\begin{array}{c}-2.81 \mathrm{E}-03 \\
(0.01)\end{array}$ & $\begin{array}{l}3.29 \mathrm{E}-03 \\
\quad(0.01)\end{array}$ & $\begin{array}{l}5.58 \mathrm{E}-03 \\
(0.01)\end{array}$ & 0.01 \\
\hline \multicolumn{6}{|l|}{ Infrastructures } \\
\hline AIRPORTDENS & $\begin{array}{c}-0.92 \\
(2.38)\end{array}$ & $\begin{array}{l}-3.18 \\
(1.95)\end{array}$ & $\begin{array}{c}-2.56 \\
(2.08)\end{array}$ & $\begin{array}{c}0.15 \\
(2.46)\end{array}$ & 3.33 \\
\hline RAILDENS & $\begin{array}{c}0.02 \\
(0.02)\end{array}$ & $\begin{array}{c}0.02 \\
(0.03)\end{array}$ & $\begin{array}{c}0.02 \\
(0.02)\end{array}$ & $\begin{array}{c}0.04 \\
(0.02)\end{array}$ & 0.02 \\
\hline ROADDENS & $\begin{array}{c}-0.01 \\
(0.01)\end{array}$ & $\begin{array}{c}-0.01 \\
(0.01)\end{array}$ & $\begin{array}{c}-0.01 \\
(0.01)\end{array}$ & $\begin{array}{c}-0.01 \\
(0.01)\end{array}$ & 0.00 \\
\hline TELF & $\begin{array}{c}2.27 \mathrm{E}-03 \\
(1.17 \mathrm{E}-03)\end{array}$ & $\begin{array}{c}6.81 \mathrm{E}-04 \\
(9.20 \mathrm{E}-04)\end{array}$ & $\begin{array}{c}1.85 \mathrm{E}-03 \\
(7.62 \mathrm{E}-04)\end{array}$ & $\begin{array}{c}3.70 \mathrm{E}-03 \\
(6.99 \mathrm{E}-04)\end{array}$ & $3.02 \mathrm{E}-03$ \\
\hline \multicolumn{6}{|l|}{ Socio-geographic } \\
\hline EMPDENS & $\begin{array}{c}7.71 \mathrm{E}-04 \\
(1.39 \mathrm{E}-03)\end{array}$ & $\begin{array}{l}-7.29 \mathrm{E}-04 \\
(1.45 \mathrm{E}-03)\end{array}$ & $\begin{array}{c}1.91 \mathrm{E}-03 \\
(1.20 \mathrm{E}-03)\end{array}$ & $\begin{array}{c}2.40 \mathrm{E}-03 \\
(1.82 \mathrm{E}-03)\end{array}$ & $3.13 \mathrm{E}-03$ \\
\hline DISTCAP & $\begin{array}{l}-2.12 \mathrm{E}-06 \\
(3.86 \mathrm{E}-06)\end{array}$ & $\begin{array}{l}-5.77 \mathrm{E}-06 \\
(3.77 \mathrm{E}-06)\end{array}$ & $\begin{array}{l}-2.09 \mathrm{E}-06 \\
(5.60 \mathrm{E}-06)\end{array}$ & $\begin{array}{c}2.80 \mathrm{E}-07 \\
(4.90 \mathrm{E}-06)\end{array}$ & $6.05 \mathrm{E}-06$ \\
\hline HAZARD & $\begin{array}{l}-1.81 \mathrm{E}-05 \\
(2.15 \mathrm{E}-05)\end{array}$ & $\begin{array}{l}-3.54 \mathrm{E}-05 \\
(2.75 \mathrm{E}-05)\end{array}$ & $\begin{array}{l}-1.41 \mathrm{E}-05 \\
(2.19 \mathrm{E}-05)\end{array}$ & $\begin{array}{l}-8.96 \mathrm{E}-07 \\
(2.07 \mathrm{E}-05)\end{array}$ & $3.45 \mathrm{E}-05$ \\
\hline URT & $\begin{array}{c}-0.03 \\
(0.02)\end{array}$ & $\begin{array}{c}-0.04 \\
(0.02)\end{array}$ & $\begin{array}{c}-0.03 \\
(0.02)\end{array}$ & $\begin{array}{c}-0.02 \\
(0.02)\end{array}$ & 0.02 \\
\hline & $\mathrm{k}=5$ & $\mathrm{k}=15$ & min_dist & Q2 & \\
\hline $\begin{array}{l}\text { Moran's I } \\
\text { p-value }\end{array}$ & $\begin{array}{l}0.02 \\
0.24\end{array}$ & $\begin{array}{l}0.01 \\
0.17\end{array}$ & $\begin{array}{r}-0.02 \\
0.10\end{array}$ & $\begin{array}{c}-2.25 \mathrm{E}-03 \\
0.36\end{array}$ & \\
\hline
\end{tabular}

Notes: Standard errors in parentheses. Moran's I test statistics calculated for two different specifications of the weights matrix: k-nearest neighbours and cut-off distance.

can be interpreted as evidence of the consistency of the local-linear estimator with spatially dependent observations (Jenish 2012). This similarity may be determined by the spatial dependence between the empirical proxies for regional growth determinants that, ultimately, generate an overlap between locally averaging in the geographical and variables spaces.

There are two advantages from using a local-linear kernel estimation instead of a GWR. First, standard errors for the partial effects are smaller than those for the GWR parameters. Therefore, results from local-linear kernel regressions are more informative about the determi- 
nants of regional growth differences in the EU. Second, it is difficult to draw objective conclusions about non-linear effects from the estimated parameters of a GWR. The reason is that, in this case, the bandwidth is a global parameter that is used in all local models and, hence, it is not variable-specific. Thus, the analysis of non-linearities should be based on subjective judgements from the distribution of the estimated coefficients.

These two considerations are in line with the arguments posed by Wheeler and Páez (2010) who establish that, although GWR is well suited for estimation and prediction, it is less useful for formal statistical inference. Nevertheless, it is worth mentioning that, in contrast to the GWR, the local-linear kernel estimator does not allow us to identify spatial variations in parameter estimates. This limits our capacity to obtain relevant economic conclusions from the analysis.

\subsection{Uncovering threshold effects}

The different conclusions about the non-linear relationship between the initial level of labour productivity and its growth, derived from the local-linear cross-validation bandwidths and the estimated partial effects, lead us to look further for a specific type of non-linearities, namely, threshold effects. This has been done by comparing the density functions of the partial effects for each continuous growth determinant depending on whether or not the value of a given threshold variable is above or below its sample median.

The comparison has been carried out by applying the test of equal density functions proposed by Li et al. (2009), which is also based on the least-squares cross-validation bandwidth selection. The test statistics obtained, along with their corresponding bootstrap $p$-values (399 replications), are reported in Table 4. Each row displays the results for the variable that generates the threshold effects, that is, the variable that takes values above or below the European sample median. Each column refers to the variable that experiences the threshold effect and, thus, for which the densities of the gradients are compared.

For illustrative purposes, let us concentrate on the third row of Table 4. It contains the test statistics (and p-values) for the comparison of the distribution of the partial effects for all the continuous growth determinants in regions whose share of gross fixed-capital formation over total GVA is above the sample median (0.19) with the distribution of the partial effects in regions whose investment in physical capital is below this threshold value. The first and second columns refer to the comparison of how the partial effects for the initial level of labour productivity and the population growth rate, respectively, are distributed for these two groups of regions. It can be observed that, while the null hypothesis of equal density functions is rejected for the partial effects of the initial level of GVA per worker $(p$-value $=0.00)$, this is not the case for the partial effects of the effective rate of depreciation $(p$-value $=0.11)$.

Focusing on the strongest rejections, and thinking in terms of groups of variables, it can be stated that the highest number of rejections are found for the neoclassical and the endogenous growth determinants, especially educational level. On the contrary, the variables least prone to induce threshold effects are the socio-geographic ones, namely, the distance from the capital and the unemployment rate. Furthermore, neoclassical growth variables are found to be the ones more affected by this type of non-linearity. This is especially the case for the share of gross fixed-capital formation over total GVA. It is also found that the sum of all weighted hazard values is widely affected by threshold effects.

To sum up, our analysis suggests that the neoclassical growth determinants are the variables that show a stronger non-linear relationship with regional growth in terms of threshold effects. These findings are confirmed by the kernel density functions of the estimated gradients plotted in Figure 1. They represent the partial effects of the variables more affected by this type of 
Table 4. Threshold analysis in the partial effects of continuous regional growth determinants

\begin{tabular}{|c|c|c|c|c|c|c|c|}
\hline & GVAPW & GPOP & SHGFCF & SHSH & HRSTCORE & PATENT & PATENTSHHT \\
\hline GVAPW & $\begin{array}{c}26.44 \\
(0.00)\end{array}$ & $\begin{array}{c}7.30 \\
(0.00)\end{array}$ & $\begin{array}{l}15.49 \\
(0.00)\end{array}$ & $\begin{array}{l}16.25 \\
(0.00)\end{array}$ & $\begin{array}{c}4.83 \\
(0.00)\end{array}$ & $\begin{array}{c}18.55 \\
(0.00)\end{array}$ & $\begin{array}{c}3.35 \\
(0.00)\end{array}$ \\
\hline GPOP & $\begin{array}{l}13.53 \\
(0.00)\end{array}$ & $\begin{array}{c}5.98 \\
(0.00)\end{array}$ & $\begin{array}{c}6.95 \\
(0.00)\end{array}$ & $\begin{array}{c}9.80 \\
(0.00)\end{array}$ & $\begin{array}{c}4.58 \\
(0.00)\end{array}$ & $\begin{array}{c}2.67 \\
(0.00)\end{array}$ & $\begin{array}{c}4.10 \\
(0.00)\end{array}$ \\
\hline SHGFCF & $\begin{array}{c}7.78 \\
(0.00)\end{array}$ & $\begin{array}{c}1.74 \\
(0.11)\end{array}$ & $\begin{array}{l}15.65 \\
(0.00)\end{array}$ & $\begin{array}{c}5.65 \\
(0.00)\end{array}$ & $\begin{array}{c}8.40 \\
(0.00)\end{array}$ & $\begin{array}{c}0.82 \\
(0.00)\end{array}$ & $\begin{array}{c}6.40 \\
(0.05)\end{array}$ \\
\hline SHSH & $\begin{array}{l}21.21 \\
(0.00)\end{array}$ & $\begin{array}{c}2.39 \\
(0.00)\end{array}$ & $\begin{array}{l}41.28 \\
(0.00)\end{array}$ & $\begin{array}{c}7.66 \\
(0.00)\end{array}$ & $\begin{array}{c}9.12 \\
(0.00)\end{array}$ & $\begin{array}{c}-0.77 \\
(0.00)\end{array}$ & $\begin{array}{c}1.43 \\
(0.00)\end{array}$ \\
\hline HRSTCORE & $\begin{array}{l}14.48 \\
(0.00)\end{array}$ & $\begin{array}{c}5.97 \\
(0.00)\end{array}$ & $\begin{array}{c}23.06 \\
(0.00)\end{array}$ & $\begin{array}{c}6.29 \\
(0.00)\end{array}$ & $\begin{array}{c}8.21 \\
(0.00)\end{array}$ & $\begin{array}{c}4.12 \\
(0.00)\end{array}$ & $\begin{array}{c}3.06 \\
(0.00)\end{array}$ \\
\hline PATENT & $\begin{array}{c}23.68 \\
(0.00)\end{array}$ & $\begin{array}{l}10.71 \\
(0.00)\end{array}$ & $\begin{array}{l}17.69 \\
(0.00)\end{array}$ & $\begin{array}{l}19.24 \\
(0.00)\end{array}$ & $\begin{array}{c}1.17 \\
(0.00)\end{array}$ & $\begin{array}{c}21.44 \\
(0.00)\end{array}$ & $\begin{array}{c}5.83 \\
(0.00)\end{array}$ \\
\hline PATENTSHHT & $\begin{array}{c}5.36 \\
(0.00)\end{array}$ & $\begin{array}{c}-0.68 \\
(0.01)\end{array}$ & $\begin{array}{c}7.98 \\
(0.00)\end{array}$ & $\begin{array}{c}1.24 \\
(0.59)\end{array}$ & $\begin{array}{c}6.64 \\
(0.00)\end{array}$ & $\begin{array}{r}-11.57 \\
(0.01)\end{array}$ & $\begin{array}{c}3.90 \\
(0.02)\end{array}$ \\
\hline RAILDENS & $\begin{array}{c}3.60 \\
(0.00)\end{array}$ & $\begin{array}{c}3.04 \\
(0.02)\end{array}$ & $\begin{array}{c}7.29 \\
(0.00)\end{array}$ & $\begin{array}{c}8.46 \\
(0.00)\end{array}$ & $\begin{array}{c}-1.07 \\
(0.01)\end{array}$ & $\begin{array}{c}9.66 \\
(0.00)\end{array}$ & $\begin{array}{c}4.63 \\
(0.01)\end{array}$ \\
\hline ROADDENS & $\begin{array}{c}0.36 \\
(0.04)\end{array}$ & $\begin{array}{c}2.80 \\
(0.00)\end{array}$ & $\begin{array}{c}6.39 \\
(0.00)\end{array}$ & $\begin{array}{l}15.72 \\
(0.00)\end{array}$ & $\begin{array}{c}1.74 \\
(0.46)\end{array}$ & $\begin{array}{l}17.98 \\
(0.95)\end{array}$ & $\begin{array}{c}4.41 \\
(0.00)\end{array}$ \\
\hline TELF & $\begin{array}{l}13.53 \\
(0.00)\end{array}$ & $\begin{array}{c}4.39 \\
(0.00)\end{array}$ & $\begin{array}{l}17.19 \\
(0.00)\end{array}$ & $\begin{array}{l}14.99 \\
(0.00)\end{array}$ & $\begin{array}{c}-1.31 \\
(0.11)\end{array}$ & $\begin{array}{c}-7.29 \\
(0.00)\end{array}$ & $\begin{array}{c}1.75 \\
(0.00)\end{array}$ \\
\hline EMPDENS & $\begin{array}{c}4.70 \\
(0.00)\end{array}$ & $\begin{array}{c}4.89 \\
(0.00)\end{array}$ & $\begin{array}{l}11.07 \\
(0.00)\end{array}$ & $\begin{array}{c}7.75 \\
(0.00)\end{array}$ & $\begin{array}{c}4.72 \\
(0.12)\end{array}$ & $\begin{array}{l}11.06 \\
(0.00)\end{array}$ & $\begin{array}{c}6.79 \\
(0.00)\end{array}$ \\
\hline DISTCAP & $\begin{array}{c}1.45 \\
(0.00)\end{array}$ & $\begin{array}{c}-1.03 \\
(0.28)\end{array}$ & $\begin{array}{c}0.78 \\
(0.04)\end{array}$ & $\begin{array}{c}-0.29 \\
(0.02)\end{array}$ & $\begin{array}{c}0.56 \\
(0.01)\end{array}$ & $\begin{array}{c}16.71 \\
(0.01)\end{array}$ & $\begin{array}{c}2.88 \\
(0.45)\end{array}$ \\
\hline HAZARD & $\begin{array}{c}0.90 \\
(0.02)\end{array}$ & $\begin{array}{c}1.39 \\
(0.00)\end{array}$ & $\begin{array}{c}5.43 \\
(0.00)\end{array}$ & $\begin{array}{c}5.22 \\
(0.00)\end{array}$ & $\begin{array}{c}3.55 \\
(0.50)\end{array}$ & $\begin{array}{c}-6.36 \\
(0.00)\end{array}$ & $\begin{array}{c}2.47 \\
(0.00)\end{array}$ \\
\hline URT & $\begin{array}{c}2.52 \\
(0.01)\end{array}$ & $\begin{array}{c}-4.86 \\
(0.56)\end{array}$ & $\begin{array}{c}4.95 \\
(0.00)\end{array}$ & $\begin{array}{l}10.41 \\
(0.00)\end{array}$ & $\begin{array}{c}2.41 \\
(0.07)\end{array}$ & $\begin{array}{l}27.10 \\
(0.30)\end{array}$ & $\begin{array}{c}5.65 \\
(0.11)\end{array}$ \\
\hline & RAILDENS & ROADDENS & TELF & EMPDENS & DISTCAP & HAZARD & URT \\
\hline GVAPW & $\begin{array}{c}20.29 \\
(0.00)\end{array}$ & $\begin{array}{c}26.18 \\
(0.00)\end{array}$ & $\begin{array}{c}5.74 \\
(0.00)\end{array}$ & $\begin{array}{c}-1.33 \\
(0.01)\end{array}$ & $\begin{array}{c}5.71 \\
(0.00)\end{array}$ & $\begin{array}{c}29.33 \\
(0.00)\end{array}$ & $\begin{array}{c}10.22 \\
(0.00)\end{array}$ \\
\hline GPOP & $\begin{array}{l}11.68 \\
(0.00)\end{array}$ & $\begin{array}{c}5.88 \\
(0.00)\end{array}$ & $\begin{array}{c}7.93 \\
(0.00)\end{array}$ & $\begin{array}{c}-2.33 \\
(0.03)\end{array}$ & $\begin{array}{c}4.66 \\
(0.00)\end{array}$ & $\begin{array}{l}18.38 \\
(0.00)\end{array}$ & $\begin{array}{c}9.28 \\
(0.00)\end{array}$ \\
\hline SHGFCF & $\begin{array}{c}2.73 \\
(0.01)\end{array}$ & $\begin{array}{c}-0.24 \\
(0.00)\end{array}$ & $\begin{array}{l}11.68 \\
(0.00)\end{array}$ & $\begin{array}{c}6.92 \\
(0.25)\end{array}$ & $\begin{array}{c}2.91 \\
(0.01)\end{array}$ & $\begin{array}{c}8.89 \\
(0.00)\end{array}$ & $\begin{array}{c}0.83 \\
(0.29)\end{array}$ \\
\hline SHSH & $\begin{array}{c}6.52 \\
(0.00)\end{array}$ & $\begin{array}{c}4.52 \\
(0.00)\end{array}$ & $\begin{array}{c}3.33 \\
(0.00)\end{array}$ & $\begin{array}{c}1.15 \\
(0.00)\end{array}$ & $\begin{array}{l}12.03 \\
(0.00)\end{array}$ & $\begin{array}{l}12.66 \\
(0.00)\end{array}$ & $\begin{array}{l}13.35 \\
(0.00)\end{array}$ \\
\hline HRSTCORE & $\begin{array}{c}4.10 \\
(0.00)\end{array}$ & $\begin{array}{c}5.48 \\
(0.00)\end{array}$ & $\begin{array}{c}8.03 \\
(0.00)\end{array}$ & $\begin{array}{c}-0.88 \\
(0.01)\end{array}$ & $\begin{array}{l}10.97 \\
(0.00)\end{array}$ & $\begin{array}{l}10.18 \\
(0.00)\end{array}$ & $\begin{array}{l}10.97 \\
(0.00)\end{array}$ \\
\hline PATENT & $\begin{array}{l}21.40 \\
(0.00)\end{array}$ & $\begin{array}{c}25.03 \\
(0.00)\end{array}$ & $\begin{array}{c}9.77 \\
(0.00)\end{array}$ & $\begin{array}{c}-1.24 \\
(0.01)\end{array}$ & $\begin{array}{c}9.61 \\
(0.00)\end{array}$ & $\begin{array}{c}35.12 \\
(0.00)\end{array}$ & $\begin{array}{l}15.11 \\
(0.00)\end{array}$ \\
\hline PATENTSHHT & $\begin{array}{c}0.07 \\
(0.03)\end{array}$ & $\begin{array}{c}-3.71 \\
(0.04)\end{array}$ & $\begin{array}{c}-4.43 \\
(0.05)\end{array}$ & $\begin{array}{c}-2.34 \\
(0.03)\end{array}$ & $\begin{array}{c}3.53 \\
(0.00)\end{array}$ & $\begin{array}{c}2.49 \\
(0.00)\end{array}$ & $\begin{array}{c}4.32 \\
(0.00)\end{array}$ \\
\hline RAILDENS & $\begin{array}{c}6.40 \\
(0.00)\end{array}$ & $\begin{array}{c}5.50 \\
(0.00)\end{array}$ & $\begin{array}{c}-3.20 \\
(0.00)\end{array}$ & $\begin{array}{c}1.58 \\
(0.12)\end{array}$ & $\begin{array}{c}7.00 \\
(0.00)\end{array}$ & $\begin{array}{c}6.45 \\
(0.00)\end{array}$ & $\begin{array}{c}12.89 \\
(0.00)\end{array}$ \\
\hline ROADDENS & $\begin{array}{c}3.33 \\
(0.00)\end{array}$ & $\begin{array}{c}2.43 \\
(0.00)\end{array}$ & $\begin{array}{l}10.12 \\
(0.94)\end{array}$ & $\begin{array}{c}-0.50 \\
(0.00)\end{array}$ & $\begin{array}{c}4.76 \\
(0.00)\end{array}$ & $\begin{array}{c}6.52 \\
(0.00)\end{array}$ & $\begin{array}{c}13.12 \\
(0.00)\end{array}$ \\
\hline TELF & $\begin{array}{c}7.15 \\
(0.00)\end{array}$ & $\begin{array}{l}11.76 \\
(0.00)\end{array}$ & $\begin{array}{c}0.70 \\
(0.00)\end{array}$ & $\begin{array}{c}0.78 \\
(0.27)\end{array}$ & $\begin{array}{c}3.82 \\
(0.00)\end{array}$ & $\begin{array}{l}16.87 \\
(0.00)\end{array}$ & $\begin{array}{l}33.01 \\
(0.00)\end{array}$ \\
\hline EMPDENS & $\begin{array}{l}14.31 \\
(0.00)\end{array}$ & $\begin{array}{l}11.79 \\
(0.00)\end{array}$ & $\begin{array}{c}2.91 \\
(0.00)\end{array}$ & $\begin{array}{c}-0.78 \\
(0.00)\end{array}$ & $\begin{array}{c}2.46 \\
(0.00)\end{array}$ & $\begin{array}{l}15.87 \\
(0.00)\end{array}$ & $\begin{array}{l}23.76 \\
(0.00)\end{array}$ \\
\hline DISTCAP & $\begin{array}{c}-4.56 \\
(0.18)\end{array}$ & $\begin{array}{c}5.29 \\
(0.81)\end{array}$ & $\begin{array}{c}-0.99 \\
(0.01)\end{array}$ & $\begin{array}{c}0.80 \\
(0.00)\end{array}$ & $\begin{array}{c}1.08 \\
(0.01)\end{array}$ & $\begin{array}{c}0.95 \\
(0.01)\end{array}$ & $\begin{array}{c}1.65 \\
(0.06)\end{array}$ \\
\hline HAZARD & $\begin{array}{c}-0.31 \\
(0.00)\end{array}$ & $\begin{array}{c}4.54 \\
(0.01)\end{array}$ & $\begin{array}{c}-2.41 \\
(0.00)\end{array}$ & $\begin{array}{c}-1.16 \\
(0.02)\end{array}$ & $\begin{array}{c}1.81 \\
(0.01)\end{array}$ & $\begin{array}{c}7.20 \\
(0.00)\end{array}$ & $\begin{array}{c}5.82 \\
(0.00)\end{array}$ \\
\hline URT & $\begin{array}{l}13.94 \\
(0.00)\end{array}$ & $\begin{array}{c}5.66 \\
(0.00)\end{array}$ & $\begin{array}{c}18.54 \\
(0.03)\end{array}$ & $\begin{array}{c}0.64 \\
(0.84)\end{array}$ & $\begin{array}{c}2.83 \\
(0.01)\end{array}$ & $\begin{array}{l}12.73 \\
(0.00)\end{array}$ & $\begin{array}{c}5.63 \\
(0.00)\end{array}$ \\
\hline
\end{tabular}

Notes: Reported values correspond to the $\hat{T}_{n}$ test statistic for equality of distributions of Li et al. (2009). Bootstrap p-values in parentheses (399 replications). 
non-linearity depending on whether the initial level of GVA per worker of its corresponding region is above or below the European median (3.69). It can be observed in the upper left-hand graph that the distribution of the partial effects for the regions with a lower initial level of labour productivity is located to the left of the distribution of the effects for the regions with higher initial productivity levels. Given the negative values of these gradients, this result implies that regions that had a lower labour productivity level at the beginning of the period analysed have converged at a faster rate.

The densities plotted in the upper right-hand graph of Figure 1 show that the negative estimated partial effects for physical capital investment are mainly found in regions that had an initial level of GVA per worker above the EU median. Moreover, the distribution of the gradients for regions whose the threshold variable is below the sample median tend to have not only positive but also higher values. This finding implies that the productivity of physical capital is higher in the less developed regions at the beginning of the period analysed. The comparisons between density functions displayed in the lower part of Figure 1 reflect that the heterogeneity of the effects of educational level and the sum of all weighted hazard values is greater for regions whose threshold variable takes values below the EU median. That is to say, human capital accumulation and geographical risks have a clear positive and negative effect, respectively, for regions with a higher initial level of labour productivity. The probability in the tails also suggests that human capital endowment can exert an important positive influence on growth in the less productive regions. The latter also experience greater adverse effects of geographic risks on growth.

Figure 2 represents the comparisons of how the estimated partial effects for the same variables as before are distributed, but now considering the share of highly educated people in
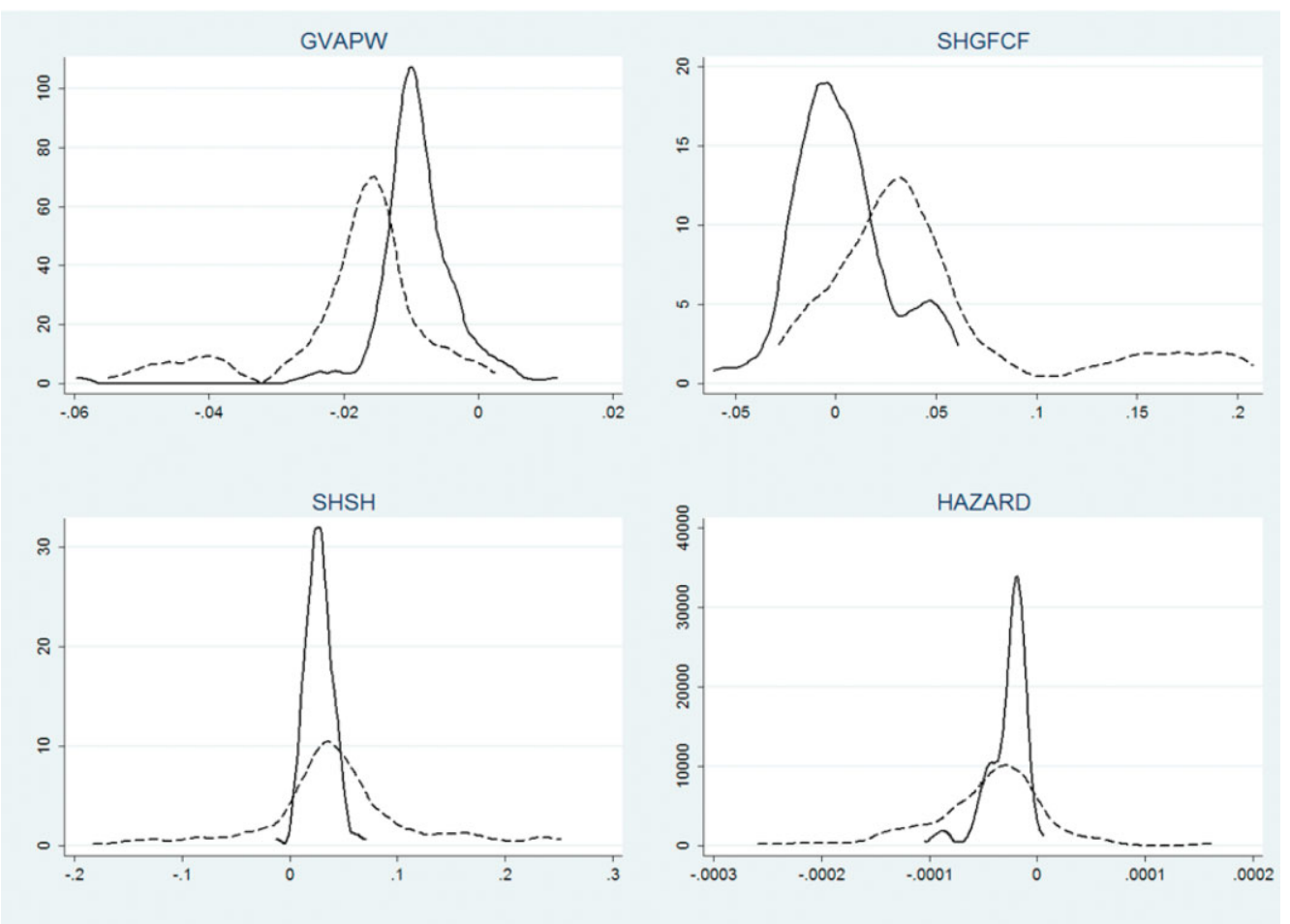

Fig. 1. Partial effects for selected regional growth determinants. Kernel density estimation. Threshold variable: GVAPW. Above (solid) and below (dashed) median 

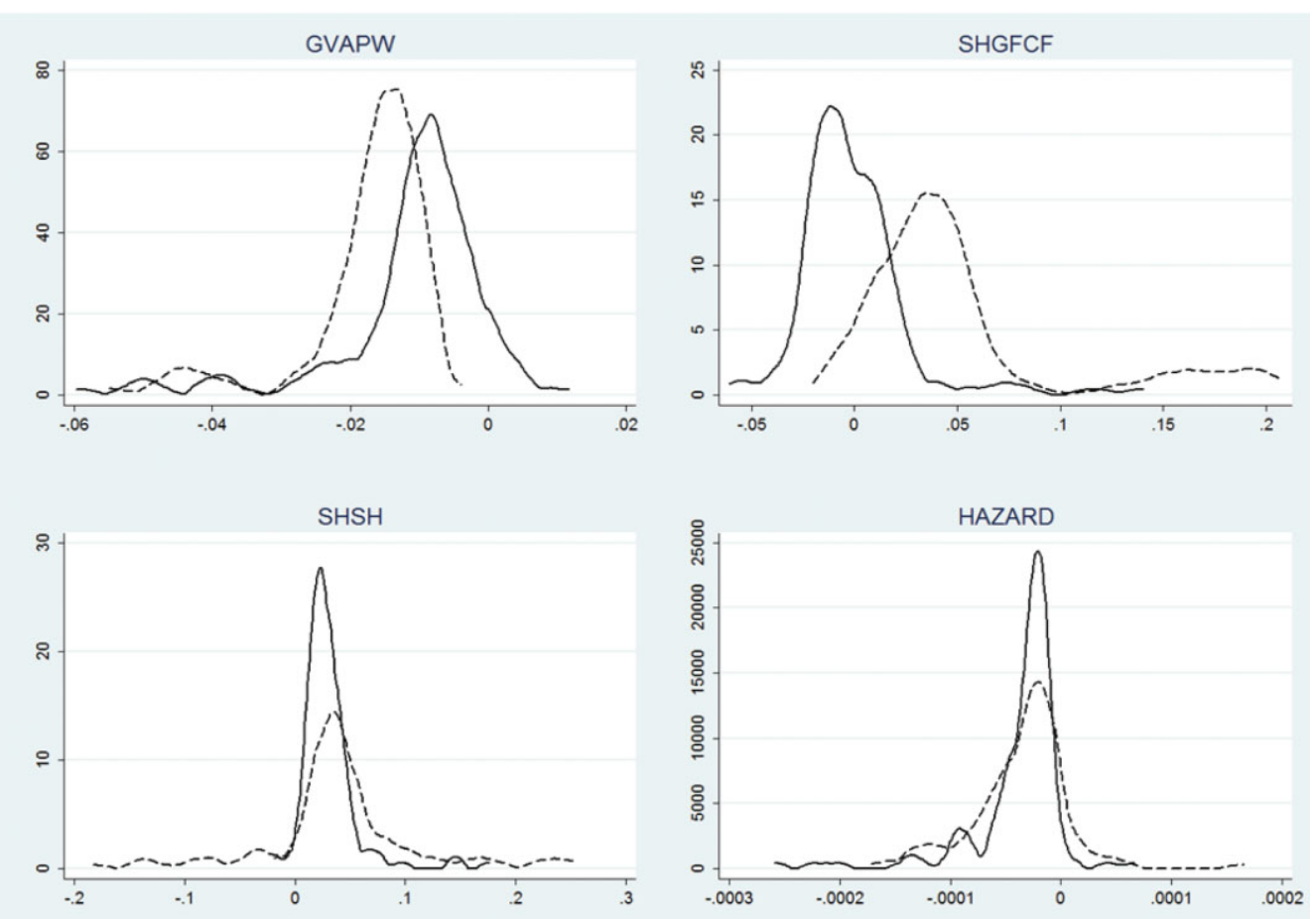

Fig. 2. Partial effects for selected regional growth determinants. Kernel density estimation. Threshold variable: SHSH. Above (solid) and below (dashed) median

the working age population as the threshold variable. The differences found are of a similar nature to those induced by the initial level of GVA per worker. Nevertheless, they are less pronounced for the effects of human capital endowment and the sum of all weighted hazard values. The distributions in the upper left-hand of this figure suggest that regions with lower levels of human capital converged faster. Furthermore, the graph in the upper right-hand shows that the upper tail of the distribution of the estimated gradients for physical capital accumulation is longer for regions where the educational level is below the European median. This result can be interpreted as evidence of the higher complementarity between human and physical capital accumulation in the less educated regions.

\subsection{Discussion}

In a recent paper, Schneider and Wagner (2012) apply a non-parametric Lasso estimator in order to determine the variables that are relevant for explaining growth differences between European NUTS 2 regions. As in the case of the local-constant kernel estimator and its corresponding least-squares cross-validation bandwidth selection rule applied in the present paper, their methodology allowed them to simultaneously deal with both model selection and parameter estimation. These authors conclude that initial GDP per capita, human capital accumulation and containing the capital city are robust determinants for regional growth in Europe. These results are in line with those of Crespo-Cuaresma et al. (2011, 2014) and Crespo-Cuaresma and Feldkircher (2013) applying Bayesian model averaging methods. These studies also find that labour market characteristics (Schneider and Wagner 2012) and both transport 
(Crespo-Cuaresma et al. 2014) and telecommunications (Crespo-Cuaresma and Feldkircher 2013) infrastructures explain growth. All these results are similar to those reported in the present paper.

Despite using a different specification, we also provide evidence that R\&D activities and their innovation results and socio-geographic variables explain growth. In contrast to Crespo-Cuaresma et al. (2011), our results suggest that physical capital accumulation is related to growth when adopting both a between and a within-country perspective. More interestingly, we conclude that variables related to endogenous growth theories (educational level, R\&D activities and innovation) are not relevant for explaining regional growth differences when country-specific factors are controlled for.

Adopting a similar approach to that of Henderson et al. (2012), we go a step further and not only determine which variables are relevant for explaining growth, but also reveal which of them have a non-linear relationship with it. Our results are similar to those already established in related studies. For example, Basile and Gress (2005), Basile (2008), Basile et al. (2012) and Fotopoulos (2012) find that the initial level of income per capita exerts a non-linear influence on growth using semi-parametric methods. Nonetheless, and contrary to Azomahou et al. (2011), we also reach the same conclusion when the variables are expressed as deviations from their corresponding country-specific means. The evidence regarding the non-linear effect of human capital accumulation on growth reinforces that provided by Basile and Gress (2005) and Basile (2008).

We also find a non-linear influence of investment in physical capital (Basile et al. 2012) and, when country fixed-effects are controlled for, of population growth and the unemployment rate. Finally, our results suggest a non-linear relationship between transport and telecommunication infrastructures and growth in the European regions. The latter can be considered a novelty in the related literature.

\section{Concluding remarks}

Non-parametric kernel estimation methods have been applied in this paper to jointly deal with the selection of variables and the identification of non-linearities in regional growth regressions. Although these methods do not explicitly take into account the spatial dimension of the data, it has been confirmed in our analysis that these methods can still be consistent when the observations are spatially dependent. The use of kernel regressions has allowed us to avoid the trade-off present in other studies that rely on the implementation of semi-parametric models between the estimation of spatial parameters and the identification of non-linearities. Hence, our results are not conditioned by the specification of the spatial dependence among regions. In addition, we show that the partial effects from the local-linear kernel estimator are more efficient that those obtained using geographically weighted regressions, from which it is much more difficult to draw objective conclusions regarding the presence of non-linearities. Nevertheless, it is worth noting that we are not able to identify spatial variations in parameter estimates.

In line with previous related studies, we obtain evidence of a non-linear relationship between growth and its determinants. These non-linearities take the form of both parameter heterogeneity and threshold effects and mainly affect the initial level of labour productivity and human capital endowment. Our results also suggest that transport and telecommunications infrastructures exert a non-linear influence on growth. These findings regarding the presence of spatial heterogeneity in the effects of some regional growth determinants should be incorporated in future research when specifying semi-parametric spatial models. This evidence should also be taken into account in order to extend the model space of model averaging exercises in the search for robust regional growth determinants. Last, but not least, policy design in the European Union should 
take into account not only that the regions have different characteristics, but also that the latter exert a different influence on growth in each region. This can be interpreted as an argument supporting the 'place-based' reform of EU Cohesion Policy.

\section{References}

Abreu M, de Groot H, Florax R (2005) A meta-analysis of $\beta$-convergence: The legendary 2\%. Journal of Economic Surveys 19: 389-420

Azariadis C, Drazen A (1990) Threshold externalities in economic development. Quarterly Journal of Economics 105: $501-526$

Azomahou TT, El Ouardighi J, Nguyen-Van P, Cuong Pham TK (2011) Testing convergence of European regions: A semi-parametric approach. Economic Modelling 28: 1202-1210

Barro R (1990) Government spending in a simple model of endogenous growth. Journal of Political Economy 98: $103-125$

Barro R, Sala-i-Martín X (1991) Convergence across states and regions. Brookings Papers on Economic Activity 1: $107-182$

Basile R (2008) Regional economic growth in Europe: A semi-parametric spatial dependence approach. Papers in Regional Science 87: 527-545

Basile R (2009) Productivity polarization across regions in Europe. The role of non-linearities and spatial dependence. International Regional Science Review 31: 92-115

Basile R, Capello R, Caragliu A (2012) Technological interdependence and regional growth in Europe: Proximity and synergy in knowledge spillovers. Papers in Regional Science 91: 697-722

Basile R, Gress B (2005) Semi-parametric spatial auto-covariance models of regional growth in Europe. Région et Développement 21: 93-118

Borts GH, Stein JL (1964) Economic growth in a free market. Columbia University Press, New York

Brunsdon C, Fotheringham AS, Charlton M (1996) Geographically weighted regression: A method for exploring spatial nonstationarity. Geographical Analysis 28: 281-298

Crespo-Cuaresma J, Doppelhofer G, Feldkircher M (2014) The determinants of economic growth in European regions. Regional Studies 48: 44-67

Crespo-Cuaresma J, Feldkircher M (2013) Spatial filtering, model uncertainty and the speed of income convergence in Europe. Journal of Applied Econometrics 28: 720-741

Crespo-Cuaresma J, Foster N, Stehrer R (2011) Determinants of regional economic growth by quantile. Regional Studies 45: 809-826

Durlauf SN, Johnson PA (1995) Multiple regimes and cross-country growth behaviour. Journal of Applied Econometrics 10: $365-384$

Eckey HF, Dreger C, Türck M (2009) Regional convergence in the enlarged European Union. Applied Economics Letters 16: 1805-1808

Ertur C, Koch W (2007) Growth, technological interdependence and spatial externalities: Theory and evidence. Journal of Applied Econometrics 22: 1033-1062

Fan J, Gijbels I (1996) Local polynomial modelling and its applications. Chapman and Hall, London

Fiaschi D, Lavezzi AM (2007) Productivity polarization and sectoral dynamics in European regions. Journal of Macroeconomics 29: 612-637

Fotopoulos G (2012) Non-linearities in regional economic growth and convergence: The role of entrepreneurship in the European Union regions. Annals of Regional Science 48: 719-741

Galor O (1996) Convergence? Inferences from theoretical models. Economic Journal 106: 1056-1069

Halleck Vega S, Elhorst JP (2013) On spatial econometric models, spillover effects, and W. University of Groningen, Mimeo

Henderson DJ, Papageorgiou C, Parmeter CF (2012) Growth empirics without parameters. Economic Journal 122: $125-154$

Jenish N (2012) Non-parametric spatial regression under near-epoch dependence. Journal of Econometrics 167: 224-239

Krugman P (1991) Increasing returns and economic geography. Journal of Political Economy 99: 483-499

Li Q, Maasoumi E, Racine JS (2009) A non-parametric test for equality of distributions with mixed categorical and continuous data. Journal of Econometrics 148: 186-200

Li Q, Racine JS (2004) Cross-validated local linear non-parametric regression. Statistica Sinica 14: 485-512

Li Q, Racine JS (2007) Non-parametric econometrics. Theory and practice. Princeton University Press, Princeton, NJ

López-Bazo E, Vayá E, Arts M (2004) Regional externalities and growth: Evidence from European regions. Journal of Regional Science 44: 43-73 
Lucas R (1988) On the mechanics of economic development. Journal of Monetary Economics 22: 3-42

Mankiw NG, Romer D, Weil DN (1992) A contribution to the empirics of economic growth. Quarterly Journal of Economics 107: 407-437

Masanjala WH, Papageorgiou C (2004) The Solow model with CES technology: Non-linearities and parameter heterogeneity. Journal of Applied Econometrics 19: 171-201

McMillen DP (2010) Issues in spatial data analysis. Journal of Regional Science 50: 119-141

R Core Team (2013) R: A language and environment for statistical computing. R Foundation for Statistical Computing, Vienna

Robinson PM (2011) Asymptotic theory for non-parametric regression with spatial data. Journal of Econometrics 165: 5-19

Romer PM (1986) Increasing returns and long-run growth. Journal of Political Economy 94: 1002-1037

Romer PM (1990). Endogenous technological change. Journal of Political Economy 98: 71-102

Schneider U, Wagner M (2012) Catching growth determinants with the adaptive Lasso. German Economic Review 13: $71-85$

Solow RM (1956) A contribution to the theory of economic growth. Quarterly Journal of Economics 70: 65-94

Unwin DJ (1996) GIS, spatial analysis and spatial statistics. Progress in Human Geography 20: 540-551

Wheeler DC, Páez A (2010) Geographically weighted regression. In: Fischer MM, Getis A (eds) Handbook of applied spatial analysis: Software tools, methods and applications. Springer-Verlag, Berlin 
Resumen. Este artículo analiza los determinantes del crecimiento económico regional en la Unión Europea mediante la adopción de un enfoque no paramétrico. Aunque el estimador de tipo núcleo local-lineal que se aplicó no toma en cuenta de manera explícita la dimensión espacial de los datos, se encontró que era coherente dentro de nuestro contexto. Además, la regresión ponderada geográficamente resulta ser menos eficiente. Obtuvimos pruebas de una relación no lineal entre el crecimiento regional y sus determinantes, en forma de heterogeneidad paramétrica y efectos umbral. Estas no linealidades afectan principalmente a la productividad inicial de la mano de obra, la dotación de capital humano y, como novedad, el nivel de las infraestructuras.

要約: 本論文は、ノンパラメトリック・アプローチにより、欧州連合の地域的経済成長の決定要因 を分析する。使用する局所線形カーネル推定量はデータの空間的次元を明示的に考慮していないが、 これは我々の目的と整合的である。さらに、地域の加重平均回帰が効率的ではないことが分かる。 パラメータの多様性と閾值において、地域の成長とその決定要因が非線形関係となるエビデンスが 得られた。非線形性は主に、初期労働生産性、人的資本存在量、また注目寸べきものとしてインフ ラストラクチャーのレベルに影響を与える。 